\title{
EL CONTROL JUDICIAL DE LOS ESTADOS DE EXCEPCIÓN CONSTITUCIONAL: LA SUPREMACÍA DEL PRESIDENTE DE LA REPÚBLICA
}

\author{
JUDICIAL REVIEW AND STATES OF EMERGENCE: THE SUPREMACY \\ OF THE EXECUTIVE BRANCH
}

\author{
Luis Alejandro Silva IrarráZaVal*
}

\begin{abstract}
RESUMEN: Se postula que el Poder Judicial es incompetente para controlar la decisión del Presidente de la República que declara un estado de excepción constitucional. A esta proposición subyace la idea de que hay supuestos en que los jueces no pueden invocar la Constitución como una norma directa e inmediatamente aplicable. Esto conlleva afirmar que el Presidente de la República tiene prioridad sobre el Poder Judicial para interpretar el texto constitucional en relación con las condiciones para decretar un estado de excepción.
\end{abstract}

Palabras clave: Estados de excepción; Presidente de la República; supremacía constitucional

ABSTRACT: Is the Presidential Power to declare states of emergence immune to judicial review? This is the key question addressed in this article. Based on legal arguments as well as historical, comparative, doctrinal and case-based arguments, we conclude that the Executive Branch is above the Judicial Power when it comes to interpret the emergency rule. Underlying this statement rests the idea that the text of the Constitution is not wholly enforceable by the judiciary.

Keywords: States of emergence; President of the Republic; supremacy of the Constitution

\section{INTRODUCCIÓN}

Vivimos una época en que la política se judicializa. Un signo de este fenómeno es el protagonismo creciente de los jueces en la vida pública, revestidos con la autoridad de ser los garantes últimos de la supremacía constitucional. La competencia del poder jurisdiccional se ha abierto camino hacia esferas cada vez más amplias con el argumento de que la Constitución es una norma directamente aplicable. Esta expansión de su poder amenaza con posicionarlos como árbitros de todo conflicto, sofocando así la legítima autonomía de lo político o, derechamente, convirtiéndolos en políticos.

Este artículo postula la existencia de un ámbito inmune al control jurisdiccional. La tesis consiste en afirmar la incompetencia del Poder Judicial para controlar los decretos que declaran un estado de excepción constitucional. Esta tesis implica afirmar la prioridad del Presidente de la República sobre los jueces para interpretar el texto de la Constitución

\footnotetext{
* Doctor en Derecho. Profesor de Derecho Constitucional de la Facultad de Derecho de la Universidad de los Andes, Chile. Dirección postal: Mons. Álvaro del Portillo 12.455, Las Condes, Santiago de Chile. Dirección electrónica:1silva@uandes.cl. El presente artículo se enmarca en el Proyecto Fondecyt Regular N 1161334. Agradezco los comentarios de Claudio Alvarado, Raúl Bertelsen y Fernando Contreras, y la colaboración de mis ayudantes tesistas Mauricio Anich y Diego Allende.
} 
respecto de los supuestos de excepción del artículo 39 de la Constitución. Con ello no estamos sosteniendo que la potestad presidencial está libre de todo control, porque dejamos intacta la competencia del Congreso; nos limitamos a negar la competencia del control judicial.

Por estrecho que sea este espacio reservado al arbitrio político del Presidente de la República, su reconocimiento entraña importantes consecuencias, teóricas al menos, en el contexto de la judicialización de la política. En efecto, esta excepción a la supremacía del Poder Judicial en la interpretación de la Constitución representa una objeción contra la premisa de que la Constitución es norma jurídica -así, sin matices- y, por lo tanto, inmediata y directamente aplicable por los jueces en cualquier circunstancia. La tesis de este trabajo, en definitiva, conduce a reconocer que la garantía última de la Constitución no descansa exclusivamente en los tribunales, sino también en los poderes políticos. Esto, a su vez, responde a que la Constitución es una realidad jurídica y política.

El trabajo se estructura en tres secciones, además de la introducción y la conclusión. En la sección II se caracteriza el problema que subyace al estudio y que cabe formular mediante la siguiente pregunta: ¿puede un tribunal de justicia controlar la constitucionalidad del decreto que declara un estado de excepción constitucional? En la sección III se ofrecen argumentos favorables al control judicial de la declaración de estados de excepción, desde diversas perspectivas: dogmática, histórica, doctrinal y de derecho comparado. En la sección IV, en cambio, se desarrollan los argumentos para sostener la inmunidad jurisdiccional del decreto presidencial, apoyados en una concepción del principio de separación de los poderes del que esos argumentos son tributarios.

\section{PLANTEAMIENTO DEL PROBLEMA}

¿Pueden los tribunales condenar al Fisco porque la Presidenta de la República no declaró oportunamente un estado de excepción constitucional? Esto es lo que se discutió en el caso Campos Herrera con Fisco de Chile, en el que un grupo de comerciantes penquistas demandó al Fisco por la demora del Gobierno en declarar el estado de catátro$\mathrm{fe}^{1}$. Aunque a primera vista la cuestión quizás parece de naturaleza administrativa (esto es, responsabilidad patrimonial del Estado por falta de servicio), lo cierto es que bajo las apariencias subyace un complejo problema constitucional. Este problema podría formularse así: ¿quién es el intérprete final del artículo 41 inciso $1^{\circ}$ de la Constitución, el Presidente de la República o la Corte Suprema?

El asunto plantea un agudo cuestionamiento a la separación entre el poder político y el judicial, discutiéndose la posibilidad de que un tribunal corrija al Ejecutivo en la ponderación de las circunstancias que justifican la declaración de un estado de excepción constitucional. Un análisis pormenorizado del caso servirá para ilustrar más vivamente el problema.

\footnotetext{
1 La misma cuestión se discutió en otros dos juicios, resueltos por la Corte Suprema en casación, con una argumentación pácticamente idéntica: ARAVENA PACHECO Y OTROS CON FISCO DE CHILE (2014) y GUZMÁN Y OTROS CON FISCO DE CHILE (2014).
} 
Como consecuencia del terremoto del 27 de febrero de 2010, el orden público experimentó una alteración significativa, particularmente en la ciudad de Concepción. La precariedad de las condiciones para atender las necesidades de los habitantes de la ciudad y la consiguiente mayor vulnerabilidad de la propiedad privada alentó los asaltos y creó un clima de intensa inseguridad. El mismo 27 de febrero la Presidenta de la República dictó el Decreto Supremo N 150, por el cual declaró Zona de Catástrofe la Región del Biobío, entre otras, y designó al Intendente de la Región como autoridad responsable de la coordinación y ejecución de los programas de recuperación ${ }^{2}$. Solo al día siguiente dictó el Decreto Supremo N ${ }^{\circ} 153$, por el que declaró la Región del Biobío en Estado de Catástofre y designó como Jefe de Defensa Nacional de la zona a un General de División del Ejército ${ }^{3}$. El 2 de marzo la Presidenta dictó el Decreto Supremo $N^{\circ} 792$, por el que delegó en el Jefe de Defensa Nacional las facultades para restringir las libertades de locomoción y reunión, disponer la requisición de bienes y limitar el ejercicio del derecho de propiedad ${ }^{4}$.

El 21 de octubre de 2010 un grupo de comerciantes de la comuna de San Pedro de la Paz, Concepción, interpuso una demanda civil en contra del Fisco, por su responsabilidad en los perjuicios económicos sufridos como consecuencia de la tardanza del Gobierno en desplegar a las Fuerzas Armadas para garantizar el orden público. El $3^{\text {er }}$ Juzgado Civil de Concepción rechazó la demanda, porque consideró que en la especie no concurrían las circunstancias que configuran la falta de servicio. La Corte de Apelaciones de Concepción confirmó la sentencia y los demandantes recurrieron de casación en el fondo. Uno de los errores de Derecho invocados en el recurso fue la infracción a los artículos 41 y 43 inciso $3^{\circ}$ de la Constitución, por la declaración extemporánea del Estado de Catástrofe.

La Corte Suprema despachó en un solo considerando la supuesta infracción constitucional de la Presidenta de la República. Conforme con el mismo texto de la Constitución, señaló, existe una prohibición explícita a los tribunales de justicia para fiscalizar el ejercicio de la potestad para declarar un estado de excepción constitucional. Y añadió: "el control jurisdiccional tiene como límite divisorio los actos que son propios de la actividad política (...) de suerte que los órganos jurisdiccionales no se encuentran autorizados para revisar decisiones de esta índole" 5 .

La cuestión planteada en este caso remite a un punto crítico en el constitucionalismo de nuestros días, que es la extensión de la competencia de los jueces en cuanto garantes del Estado de Derecho. En el contexto actual del Derecho Constitucional, en donde la protección judicial de los derechos fundamentales ha venido a convertirse en la piedra de toque de la legitimidad del sistema, afirmar la inmunidad jurisdiccional del Presidente de la República resulta, al menos, provocador. Y esto es precisamente lo que hace la sentencia Campos Herrera con Fisco de Chile.

Para efectos del análisis, conviene identificar los puntos en que se centrará la cuestión de quién es el intérprete final, si el Presidente de la República o el Poder Judicial. Una

\footnotetext{
Decreto Supremo Nº 150 de 2010.

Decreto Supremo Nº 153 de 2010.

Decreto Supremo No 792 de 2010.

Campos HerRera con Fisco de Chile (2013), cons. $12^{\circ}$.
} 
primera precisión es que el estudio se circunscribe a los actos que declaran el estado de excepción y deja fuera los que se dictan en la aplicación de dichos estados, porque el control judicial de estos actos es pacíficamente aceptado hoy. Una segunda precisión es que la pregunta sobre quién es el intérprete final no excluye el control que el Congreso -un órgano político- puede efectuar sobre las actuaciones del Presidente de la República; esta posibilidad no altera la tesis, que se enfoca en la incompetencia del Poder Judicial para controlar al Ejecutivo $^{6}$.

\section{LA ÚLTIMA PALABRA ES JUDICIAL}

En esta sección se exponen cuatro argumentos contrarios a la tesis defendida en el artículo. Así, con excepción de la perspectiva jurisprudencial, que fue omitida porque no se halló material alguno, hay una defensa dogmática (A), histórica (B), doctrinal (C) y comparada (D) de la competencia judicial para controlar la declaración del estado de excepción constitucional.

\section{A. LA REForma CONSTITUCIONAL DE 2005}

El artículo 45 inciso $1^{\circ}$ de la Constitución, reformado por la Ley $\mathrm{N}^{\circ} 20.050$, dice: "Los tribunales de justicia no podrán calificar los fundamentos ni las circunstancias de hecho invocados por la autoridad para decretar los estados de excepción, sin perjuicio de lo dispuesto en el artículo 39”. Después de la reforma constitucional de 2005, el texto de la Constitución parece avalar la tesis de que el intérprete final de la potestad para declarar un estado de excepción es el Poder Judicial. En efecto, la frase "sin perjuicio de lo dispuesto en el artículo 39" debería entenderse como una autorización para que el Poder Judicial califique los fundamentos y circunstancias de hecho invocadas por la autoridad, con vistas a decretar los estados de excepción constitucional y así garantizar el cumplimiento del artículo 39. Esto significaría, entonces, que los tribunales de justicia pueden juzgar la decisión de la autoridad cuando se trata de verificar si: a) se da alguna de las siguientes situaciones de excepción: guerra exterior o interior, conmoción interior, emergencia y calamidad pública, y b) si, dándose alguna de aquellas situaciones, esta afecta gravemente el normal desenvolvimiento de las instituciones del Estado. Consecuentemente, el Judicial es el Poder que tendría la última palabra, porque el artículo 39 es "la norma de clausura de los estados de excepción constitucional" 7 . La coordinación entre el artículo 39 de la Constitución y la excepción del artículo 45 inciso $1^{\circ}$, la entiende Ríos como una habilitación para que los tribunales califiquen las circunstancias y fundamentos de hecho de la declaración en tres supuestos prácticamente omnicomprensivos, que absorben toda la sustancia política de la potestad presidencial ${ }^{8}$.

\footnotetext{
6 Intencionalmente, se excluyó el estudio de un posible control del Tribunal Constitucional (artículo 93 $\mathrm{N}^{\circ} 16$ ). En primer lugar, porque no es un órgano judicial y, en segundo lugar, porque se trata de un supuesto hipotético, toda vez que nunca hasta ahora se ha requerido su control.

7 Ríos (2005) pp. 337-338.

8 Ríos (2005) pp. 337-338.
} 
Por su parte, el artículo 40 inciso $3^{\circ}$ abre también un espacio para que el ejercicio del poder político pudiera entenderse sujeto al control jurisdiccional. Si se da que el Presidente de la República declara estado de sitio o de asamblea sin que el Congreso se haya pronunciado, "las medidas que adopte (...) podrán ser objeto de revisión por los tribunales de justicia, sin que sea aplicable, entre tanto, lo dispuesto en el artículo 45”. Esta remisión al artículo 45 no puede entenderse hecha sino a la prohibición de su inciso $1^{\circ}$. Esto significa que mientras el pronunciamiento del Congreso esté pendiente, los tribunales pueden calificar los fundamentos y "circunstancias de hecho invocados por la autoridad para decretar los estados de excepción" $"$.

\section{B. La EVOlUCiÓN DE los Últimos 30 aÑos}

La tendencia histórica ha sido restringir el margen de discrecionalidad política en el contexto de los poderes de excepción del Presidente de la República. Simplificando las cosas, podría decirse que primero el Congreso y luego los tribunales de justicia han reclamado y obtenido su reconocimiento como agentes de control del Poder Ejecutivo. Esta tendencia parece haber llegado a un punto en que el Poder Judicial tiene competencia para enervar las actuaciones del Presidente, incluida la de declarar un estado de excepción constitucional.

Aunque con matices importantes, cabría afirmar que el ámbito del poder jurisdiccional ha experimentado en el tiempo una ampliación progresiva dentro del marco de los poderes excepcionales. Esta evolución es particularmente rápida en las tres últimas décadas. El texto de la Constitución aprobada en 1980 disponía en el artículo 41 № 3 que el habeas corpus era improcedente en los Estados de Asamblea y de Sitio, y que el recurso de protección tampoco procedía en ninguno de los estados de excepción, respecto de las actuaciones sujetas a la Constitución y a las leyes ${ }^{10}$. Cerraba el numeral diciendo que en caso alguno los tribunales de justicia podrán "entrar a calificar los fundamentos de hecho de las medidas que haya adoptado la autoridad en el ejercicio de sus facultades". La reforma constitucional de 1989 reemplazó el numeral 3 del artículo 41 por un texto que refleja la intención de aumentar el control judicial sobre los actos ejecutados por la autoridad durante los estados de excepción constitucional. Aunque se mantuvo la prohibición de calificar los fundamentos de hecho, se eliminó la restricción impuesta a los recursos de amparo y de protección.

Finalmente, con la reforma constitucional de 2005 terminó de invertirse el carácter excepcional del control jurisdiccional, para transformarse en regla general: "respecto de las medidas particulares [adoptadas en estados de excepción] que afecten derechos constitucionales, siempre existirá la garantía de recurrir ante las autoridades judiciales" (artículo 45 inciso ${ }^{\circ}$ ). Pero se avanzó un paso más aún, traspasándose una línea que había permanecido

\footnotetext{
9 Aquí no puede pasarse por alto la aparente inconsistencia que se detecta al coordinar ambas disposiciones. Porque el artículo 40 inciso $3^{\circ}$ se refiere a "las medidas que adopte" el Presidente durante los Estados de Asamblea o de Sitio y hasta que el Congreso se pronuncie, mientras que la prohibición del artículo 45 inciso $1^{\circ}$ recae sobre la declaración misma del estado de excepción. Tampoco puede dejarse de subrayar la prácticamente nula atención prestada al punto durante la discusión parlamentaria de la reforma, exceptuando la intervención de Francisco Cumplido (ver nota 11).

10 El antecedente normativo inmediato de esta disposición es el DECRETo LEY Nº 1684 de 1977, que sustituyó el texto del artículo 14 del Acta Constitucional No 4 de 1976.
} 
intacta hasta entonces: a contar de ahora los tribunales de justicia son también competentes para calificar los fundamentos y circunstancias que motivaron la declaración de un estado de excepción constitucional. Antes de 2005, el escenario en que se había debatido la competencia del Poder Judicial era el de los actos habilitados por un estado de excepción, mas nunca el de los actos habilitantes; estos habían sido tradicionalmente considerados ajenos a la competencia judicial ${ }^{11}$. El haber abierto al conocimiento de los tribunales de justicia la discrecionalidad con que la autoridad política pondera las situaciones de excepción significa que, al parecer, la última palabra pertenece al Poder Judicial.

\section{El sometimiento a Derecho de todos los órganos del Estado}

El control judicial de los poderes de excepción ha sido defendido por parte de la doctrina nacional. En su libro "El Recurso de Protección", Eduardo Soto Kloss desarrolla un silogismo que debería concluir que los tribunales son competentes para controlar la declaración de un estado de excepción, aunque él no lo afirme explícitamente. El argumento descansa en que todos los órganos del Estado están sujetos a Derecho (premisa mayor) ${ }^{12}$. Quienes dicen lo que es el Derecho son los tribunales de justicia (premisa menor) ${ }^{13}$. Conclusión: los tribunales son competentes para controlar que el Presidente de la República se sujete a Derecho al declarar un estado de excepción constitucional ${ }^{14}$.

Bravo y Sharim se preguntan por los recursos que procederían en contra de una declaración inconstitucional del Estado de Sitio (v. gr., una declaración que no señale su duración $)^{15}$. La respuesta que ofrecen distingue entre el acto que declara el Estado de Sitio y el acto que en aplicación de aquel priva de libertad a un individuo. Para obtener la libertad mediante el recurso de amparo, el interesado tendría que solicitar por vía de excepción, a través del recurso de inaplicabilidad, la nulidad del decreto que declaró el estado de excepción. El fundamento de esta posición es lo ilógico que resulta reconocerle a los tribunales la competencia para declarar inconstitucionales las leyes y negársela respecto de los

\footnotetext{
11 Esta posición fue criticada por Jaime Castillo Velasco en 1979, reivindicando la competencia judicial para controlar las decisiones que la autoridad política adopta en función de la seguridad nacional, entre las que debemos entender se encuentra la de declarar un estado de excepción constitucional. CaSTILlo (1986) pp. 93-94. En sentido contrario puede citarse la intervención de Francisco Cumplido durante la tramitación de la reforma constitucional, quien a propósito de la modificación de la primera parte del artículo 45 inciso $1^{\circ}$ recordó "que siempre se ha entendido y aplicado en la práctica que la calificación para 'decretar' el estado de excepción es competencia exclusiva de los órganos del Estado que la Constitución, en cada caso, determina”. Historia de La LeY 20.050, p. 364.

12 Soto (1982) p. 436.

13 Soто (1982) p. 437.

14 Soto no concluye esto expresamente. Pero así, al menos, lo entendió Precht (ver nota 56). Podría pensarse que en un argumento como este se apoya el voto en contra del Ministro Muñoz en la sentencia de CAmpos Herrera con Fisco de Chile (2013). Porque allí el Ministro omite cualquier referencia al problema de la competencia judicial planteado en el voto de mayoría: su discurso sencillamente asume que la actuación de la Presidenta de la República está sujeta a las leyes del caso y conforme con ellas debe ser juzgada.

15 Bravo y Sharim (1958) pp. 183-189.
} 
decretos: "no puede haber sido la intención del Constituyente liberar al decreto de recursos o reclamaciones cuando contempló esta situación para los preceptos legales"16.

La premisa, vigente hasta la reforma de 2005 , de que estaba vedado a los tribunales pronunciarse acerca de la declaración de un estado de excepción, podía ser fácilmente reducida a un simulacro de prohibición. Un buen ejemplo de ello lo encontramos en un texto de Silva de 1986. Partiendo de la base de que se trata de una potestad política y, por tanto, fuera de la órbita del control judicial, Silva condiciona el respeto de este límite al cumplimiento de las exigencias constitucionales. Así, reserva para los tribunales de justicia la posibilidad de verificar si el estado de excepción declarado corresponde a aquellos que la Constitución reconoce como tales ${ }^{17}$; si la autoridad que declaró el estado de excepción es aquella prevista por la Constitución para hacerlo; y si la forma de la declaración se ajustó a las exigencias constitucionales (esto es, decreto firmado por el ministro respectivo) ${ }^{18}$. Estas reservas, que tienen su asiento en la propia Constitución, artículos 6, 7 y 35 inciso $1^{\text {o19 }}$, podrían entenderse como la proyección natural del texto constitucional y, por lo tanto, esencialmente respetuosas del ámbito reservado al poder político para interpretarlo. Sin embargo, basta con la primera de ellas para reconocer que se está entregando al Poder Judicial la competencia para, potencialmente, pronunciar la última palabra acerca de la constitucionalidad de la declaración de un estado de excepción.

La conclusión del párrafo anterior habría venido a ser corroborada por la reforma constitucional de 2005, según García al menos. Porque la posibilidad de que el Poder Judicial controle la circunstancia de que la situación de excepción "afecte gravemente el normal desenvolvimiento de las instituciones del Estado", como lo exige el artículo 39, permite concluir que en Chile dejó de existir "la teoría de la no justiciabilidad de los actos políticos" ${ }^{20}$. García distingue dos niveles de control judicial de la declaración de estado de excepción: el control judicial "pleno" para los casos en que el Presidente de la República declare Estado de Sitio o de Asamblea de manera provisoria, y el control judicial "limitado", por el que puede cuestionarse la existencia de los hechos en que se apoya la declaración del estado de excepción, "cualquiera que este sea"21. En la misma dirección se orienta Ríos, quien, como cabría esperar, extrae de la articulación de los artículos 39 y 45 de la Consti-

16 Bravo y SHARIm (1958) p. 188. Similar argumento, pero respecto de los decretos en general, en FonteCiLLA (1953) pp. 82 y 83.

17 Silva (1986) p. 87; Ríos (1983) p. 785, reconoce que la calificación de los hechos que justifican la declaración de un estado de excepción constitucional es prerrogativa discrecional del Ejecutivo, pero observa que esos hechos deben existir verdaderamente "y estar claramente descrito en el decreto declaratorio".

18 Silva (1986) pp. 87-89.

19 Silva (1986) p. 87.

20 García (2005) p. 460. En este argumento descansa la prevención del Ministro Brito en las sentencias Aravena Pacheco y otros con Fisco de Chile (2014) y Guzmán y otros con Fisco de Chile (2014); ver nota 62. La regla general es que los actos de gobierno "estén afectos al control judicial, más aún si estos vulneran o restringen derechos fundamentales". La única excepción posible es aquella contemplada expresamente en la Constitución. Pero la declaración de un estado de excepción no está libre del control judicial, porque el artículo 45 inciso $1^{\circ}$ segunda parte regula "en detalle ciertas contra excepciones al carácter no justiciable de tal acto de gobierno". Evidentemente se refiere a la frase "sin perjuicio de lo dispuesto en el artículo 39".

21 García (2005) p. 472. Inferimos que el control judicial "limitado" es el que resulta de la articulación entre el artículo 45 y el 39 de la Constitución. 
tución la conclusión de que los tribunales de justicia tienen una competencia amplia para controlar la declaración de un estado de excepción ${ }^{22}$.

\section{El CASO COLOMBiAnO}

El colombiano es un ejemplo particularmente expresivo de la tesis de la supremacía judicial. Allí, la Corte Constitucional está posicionada como el árbitro final de la constitucionalidad del ejercicio de los poderes excepcionales. Los presupuestos teóricos sobre los que descansa esta prerrogativa son dos. El primero es una determinada concepción de la supremacía constitucional, que implica su garantía jurisdiccional. El segundo es la naturaleza del acto que declara un estado de excepción constitucional, que se estima eminentemente jurídico y no político.

La Constitución colombiana de 1991 ofrece una detallada regulación de los estados de excepción ${ }^{23}$. Dicho estatuto representa una reacción contra la situación que se vivió en el país durante las décadas anteriores ${ }^{24}$. Particularmente, dos circunstancias explican su génesis y formulación. Por una parte, el abuso de las atribuciones del artículo 121 de la Constitución de 1886, sobre el Estado de Sitio ${ }^{25}$. Por otra, la excesiva condescendencia de la Corte Suprema de Justicia para con las actuaciones del Ejecutivo realizadas al amparo del Estado de Sitio ${ }^{26}$. De ahí que en la Constitución de 1991 se clasificaran los estados de excepción, se garantizaran los derechos fundamentales y se estableciera el control jurisdiccional de las actuaciones del Ejecutivo, entre otras innovaciones.

Hubo dos puntos que el texto de la Constitución de 1991 omitió aclarar y que eran importantes para determinar el alcance del control jurisdiccional. En primer lugar, si la naturaleza del control jurisdiccional era solo formal o también material. En segundo lugar, si los actos sujetos a control eran solo aquellos dictados en el marco del estado excepcional o también los actos por los que se declara dicho estado. Muy tempranamente, sin embargo, la Corte Constitucional resolvió estas interrogantes ${ }^{27}$. Respecto del primer punto, dijo que el control era tanto formal como material. Respecto del segundo, afirmó que la competencia de la Corte Constitucional se extiende también a las declaratorias de los estados de excepción. El motivo sobre el que se fundan ambas aclaraciones es el mismo: la garantía de la supremacía constitucional exige de la Corte Constitucional un control integral sobre los actos de los poderes estatales. Admitir que la competencia de la Corte está limitada a cuestiones formales o a los actos dictados en aplicación de un estado de excepción implica exponer a

\footnotetext{
22 Aparentemente, Ríos no ve las condiciones del artículo 39 como copulativas, porque distingue dos hipótesis que habilitan el control judicial. Por una parte, aquellos casos en que el estado de excepción declarado es inconsistente con los autorizados por la Constitución o con las situaciones de excepción previstas por la Constitución, o sencillamente carece de todo fundamento fáctico: Ríos (2009) p. 291 y Ríos (2005) p. 338. Por otra parte, cuando se incumple el requisito de que la situación de excepción afecte "gravemente el normal desenvolvimiento de las instituciones del Estado": Ríos (2009) p. 291.

23 Constitución Política de Colombia de 1991, Capítulo 6, artículos 212-215.

4 VANegas (2011) pp. 262-263.

Entre 1958 y 1978, Colombia vivió 15 años bajo Estado de Sitio, Gallón (1979).

6 ECheverri (2014) p. 14.

7 Sentencia C-004-92.
} 
la Constitución a ser desobedecida por el Presidente de la República. Más aún, renunciar a su control supondría una infracción a la Constitución por parte del mismo órgano llamado a custodiarla, la Corte Constitucional ${ }^{28}$.

La frecuencia con que el Presidente hizo uso de los poderes excepcionales durante los primeros años fue correspondida por la Corte Constitucional con un control que varias veces terminó en una declaración de inconstitucionalidad de la declaratoria de excepción ${ }^{29}$. Alentado por el deseo de afirmar su competencia frente a la detentada por la Corte Constitucional, en una ocasión el Presidente de la República desafió su jurisprudencia y envió la declaratoria al Consejo de Estado para que revisara su constitucionalidad, y no a la Corte. No obstante esto, la Corte Constitucional se avocó a su conocimiento de oficio y en la sentencia que dictó amplió el fundamento teórico de su competencia ${ }^{30}$.

Frente a la idea de que la declaratoria de un estado de excepción es un acto político y, por tanto, eximido del control jurídico, la sentencia C-802 defendió la tesis de que el acto es jurídico. El silogismo que utilizó fue el siguiente: los actos que se desarrollan dentro de la Constitución deben sujetarse a los presupuestos formales y materiales dispuestos por la Constitución (premisa mayor); el acto que declara un estado de excepción se desarrolla dentro de la Constitución (premisa menor); luego, la declaratoria debe sujetarse a la Constitución formal y materialmente (conclusión). La sentencia asume que así queda demostrada la naturaleza jurídica del acto de declaratoria y, por consiguiente, la competencia de la Corte Constitucional ${ }^{31}$.

En suma, la Corte Constitucional es el intérprete final de la regulación constitucional y estatutaria de los estados de excepción, dejándole al poder político el margen que en cada caso estime, conforme a la Constitución, para decidir sobre las causales que permiten declarar un estado de excepción.

\footnotetext{
28 Sentencia C-004-92, cons. VI-4: "si la Corte elude el control material de los decretos que declaran un estado de excepción, ello significaría que las facultades del Presidente de la República en esta materia serían supraconstitucionales. Y más aún: que esta Corte podría tolerar la actividad inconstitucional del Ejecutivo renunciando así a su deber de restablecer el imperio del Estatuto Supremo". El fundamento normativo de esta conclusión es la coordinación entre los artículos 4, 241 y 215 -parágrafo- de la Constitución. CIFUENTES (2002) p. 144: "El Presidente [de la República] está sujeto a la Constitución, y no es su guardián. [La Corte Constitucional ha de] confrontar sus actos con la Constitución, como quiera que ningún sujeto público puede ser juez de sus propios actos o carecer de control".

29 Entre 1992 y 1997 se decretaron ocho estados de excepción constitucional, de los cuales tres fueron declarados inconstitucionales por la Corte Constitucional: sentencias C-300-94, C-222-95 y C-466-97.

30 Sentencia C-802-02. La propia Constitución prevé que conozca de oficio los decretos legislativos dictados en ejercicio de los poderes excepcionales (artículo 215.6), pero dejando abierta la cuestión de si las declaratorias están incluidas o no.

31 Dice la sentencia respecto de la declaratoria: "sin desconocer que se trata de un acto que se proyecta políticamente, es evidente que el decreto mediante el cual se declara el estado de conmoción interior es un acto jurídico que contiene elementos reglados por la propia Constitución y un elemento discrecional también reconocido por la Carta": sentencia C-802-02. El uso del adjetivo evidente en este texto y en el citado en la nota precedente disimula sin elegancia la elusión de la parte del argumento que precisamente exige ser demostrado, esto es, la naturaleza jurídica del acto por el que se declara el estado de excepción constitucional.
} 


\section{LA ÚLTIMA PALABRA ES DEL PRESIDENTE DE LA REPÚBLICA}

En esta sección se desarrollan los argumentos favorables a la inmunidad jurisdiccional de la declaración de los estados de excepción. Hay dos argumentos basados en el texto de la Constitución, uno desde la perspectiva de su lógica interna (A) y otro desde una perspectiva analogia iuris (B). Luego hay un argumento histórico (C), otro doctrinal (D), al que sigue uno jurisprudencial (E), para cerrar con un argumento de Derecho comparado (F).

\section{A. LA LÓGiCA INTERna del teXto CONSTITUCiOnal}

La posición del Presidente de la República como supremo intérprete de la Constitución puede inferirse del texto de sus artículos 39 a 45. Quizá el caso más fácil se refiere al poder para declarar o no un estado de excepción constitucional. Dicha facultad, reconocida expresamente al Presidente respecto de cada uno de los cuatro estados de excepción, está dispensada del control judicial explícitamente por el artículo 45: "Los tribunales de justicia no podrán calificar los fundamentos ni las circunstancias de hecho invocados por la autoridad para decretar los estados de excepción”. Contra esta primera afirmación, podría decirse que aquello que está fuera del alcance de los tribunales es la calificación de los fundamentos y circunstancias que justifican la declaración del estado de excepción, pero que la constatación de dichos fundamentos y circunstancias, en cambio, es algo que sí les compete $^{32}$. Así, por ejemplo, los tribunales no podrían pronunciarse acerca de si la erupción de un volcán es motivo suficiente para justificar la declaración de un estado de excepción, pero sí podrían verificar si el volcán realmente ha hecho erupción. La objeción parece aceptable, porque la diferencia entre un volcán en erupción y uno que no lo está resulta, a primera vista, evidente. Sin embargo, es fácil complicar las cosas preguntando lo siguiente: ¿quién decidirá el significado del sustantivo erupción? El caso es en verdad más complicado aún, porque la Constitución guarda silencio acerca de los supuestos fácticos para declarar un estado de excepción. Luego, la diferencia entre calificar un fundamento o circunstancia de hecho y constatar su existencia es virtual; se trata de una diferencia de razón que no puede ser aprovechada por los tribunales sin transgredir la prohibición de la primera parte del artículo 45 inciso $1^{\circ}$.

Quienes sostienen esta distinción para el supuesto del artículo 45 inciso $1^{\circ}$ de la Constitución creen ser fieles al motivo de la prohibición que sería, según ellos, la discrecionalidad política con que la autoridad necesariamente debe ponderar los hechos ${ }^{33}$. Ellos aceptan que los jueces no deben sustituir el juicio de los políticos en esta materia; sin embargo, esto no excluye la competencia para constatar los hechos, porque eso no es algo entregado al arbitrio político, concluyen ${ }^{34}$. La lógica de la norma parece indicar algo distinto, pues, a juicio nuestro, la finalidad de la prohibición puede resultar completamente frustrada si se admite la competencia judicial para constatar la existencia de los hechos. Y es que al prohibir a los tribunales la calificación de los fundamentos, lo que persigue la disposición

\footnotetext{
Soto (1982) p. 442; Ríos (1983) p. 787; Silva (1986) pp. 95-98.

33 Ríos (2009) pp. 291-293.

34 Silva (1986) pp. 96-98.
} 
es garantizar la eficacia de la decisión y no, como presumen aquellos, reconocer un ámbito reservado a la prudencia política.

En congruencia con la primacía del Presidente para interpretar las causales que permiten declarar un estado de excepción está la facultad presidencial de suspender la vigencia de dichos estados. Sobre este acto nada se dice que permita sostener la competencia de los tribunales de justicia para revisarlo. Si nos atenemos al aforismo "las cosas se deshacen como se hacen”, este silencio de la norma debería interpretarse como corroboración de la inmunidad que tiene el Presidente de la República respecto de los tribunales de justicia para declarar o no un estado de excepción constitucional ${ }^{35}$.

\section{B. El SENTIDO DEL MANDATO "NO PODRÁn CALIFICAR lOS FUndAMENTOS"}

El texto de la prohibición del artículo 45 inciso $1^{\circ}$ de la Constitución "[los tribunales] no podrán calificar los fundamentos [invocados para declarar un estado de excepción]" se repite dos veces más en la misma Constitución, una en el inciso final del artículo 76 y la otra en el inciso $3^{\circ}$ del artículo 83 . En estos dos casos el texto alude a la prohibición que recae sobre la autoridad requerida por una orden para cuestionar su cumplimiento. La prohibición expresada en estas disposiciones con esa redacción brota directamente del principio de separación de los poderes, en la medida que garantiza la eficacia de las órdenes -del Poder Judicial en el caso del artículo 76; del Ministerio Público en el caso del artículo 83-, impidiendo que el llamado a ejecutarlas juzgue su mérito como condición para decidir su cumplimiento $^{36}$.

Es razonable sostener que la misma pretensión explica la frase del artículo 45 de la Constitución. Al prohibir a los tribunales de justicia la calificación de los fundamentos en

35 El mismo razonamiento podría extenderse a los demás aspectos discrecionales involucrados en la declaración: el plazo, el área geográfica afectada, los derechos afectados y el grado de afectación, allí donde la Constitución admite ese margen.

36 El texto de la primera parte del artículo 45 inciso $1^{\circ}$ fue propuesto por Pinochet en el Mensaje de la Ley $\mathrm{N}^{\circ}$ 18.825 de 1989, que reformó la Constitución. No tenemos antecedentes de su redacción, pero es razonable pensar que se tomó la letra y el espíritu del inciso $3^{\circ}$ del artículo 76 de la Constitución. La Subcomisión encargada de la Organización y Atribuciones del Poder Judicial, presidida por José María Eyzaguirre, entonces Presidente de la Corte Suprema, propuso agregar el actual inciso $2^{\circ}$ y $3^{\circ}$ del artículo 76 (en el anteproyecto era el artículo 80), "en vista de lo ocurrido durante los tres años del Gobierno del Presidente Allende" (ACTAS DE LA Comisión de Estudios de la Nueva Constitución, p. 154, Sesión 251ª de 19 de octubre de 1976). El propósito sería, dijo, "que no haya duda alguna ni pueda el día de mañana el Presidente de la República decir, como lo dijo el Presidente Allende, que él podía hacer juicios de méritos sobre las resoluciones judiciales y juzgar qué es lo que llevaría envuelta la resolución, para cumplirla o no cumplirla" (p. 155). El inciso $3^{\circ}$ del actual artículo 76 se aprobó en la Sesión $252^{\mathrm{a}}$, de 21 octubre de 1976 . Los incisos $2^{\circ}$ y $3^{\circ}$ propuestos correspondían a los incisos $1^{\circ}$ y $2^{\circ}$ del artículo 11 del Código Orgánico de Tribunales de 1943. Este artículo está copiado prácticamente en forma literal del artículo 10 de la Ley de Organización y Atribuciones de los Tribunales de Chile de 1875. "Esta prescripción del artículo 10 es consecuencia natural de la independencia de toda otra autoridad que el artículo 11 reconoce al Poder Judicial en el ejercicio de sus funciones": Risopatrón (1900) p. 15. El autor liga esta característica con el artículo 99 de la Constitución, que es nuestro actual artículo 76 inciso $1^{\circ}$ de la Constitución. Por último, deriva de este "principio de nuestro Derecho Público" (esto es, la independencia del Poder Judicial) el carácter privativo de la jurisdicción -judicial y la de los demás poderes públicos en sus respectivas esferas-, porque "aleja o excluye a los demás poderes y aún a los demás funcionarios del mismo orden judicial, de inmiscuirse en el asunto en que es llamado a conocer y juzgar el tribunal de que se trata”: Risopatrón (1900) p. 16. 
que se apoya la decisión de la autoridad para decretar un estado de excepción, la Constitución busca asegurar la eficacia de la actuación del Ejecutivo. Aquí, como en los artículos 76 y 83 de la Constitución, la norma debe entenderse como una proyección del principio de separación de los poderes, al garantizar la independencia del Presidente de la República respecto del control judicial. Así como la autoridad requerida no puede cuestionar los mandatos judiciales (artículo 76) o las órdenes del Ministerio Público (artículo 83), tampoco los jueces pueden cuestionar la decisión presidencial de decretar un estado de excepción constitucional ${ }^{37}$.

\section{LA TRADICIÓN HISTÓRICA}

A lo largo de la historia constitucional de Chile se puede comprobar cómo la garantía de la seguridad del Estado se debate entre la autonomía del Poder Ejecutivo para reaccionar según lo requieran las circunstancias, por un lado, y el control judicial y parlamentario del ejercicio de dicho poder, por otro. A grandes líneas, podría decirse que el control se ha ido configurando de acuerdo con las formas como el Ejecutivo ha usado el poder para actuar en circunstancias calificadas por él mismo como extraordinarias. En este sentido, se aprecia una clara tendencia a explicitar los límites del Poder Ejecutivo y los mecanismos para controlarlo, tendencia que refleja el interés por salvaguardar los dos principales bienes amenazados: la democracia representativa, de la que responde el Congreso, y los derechos de las personas, por los que responden los tribunales de justicia.

Hasta la reforma constitucional de 2005, las distintas constituciones testimonian la primacía del Presidente de la República para declarar los estados de excepción constitucional (aunque no siempre se hayan conocido por este nombre) ${ }^{38}$. Y cuando no lo hacen los textos constitucionales, lo hace la práctica ${ }^{39}$. Con la reforma constitucional de 2005 , en

\footnotetext{
37 La pertinencia de esta analogía se refuerza al aplicarle a los artículos 76 y 83 de la Constitución la diferencia entre constatar y calificar los supuestos de hecho de la norma (ver nota 32).

38 Es el caso del artículo $82 \mathrm{~N}^{\circ} 20$ de la Constitución de 1833, al menos en el caso de ataque exterior, LASTARRIA (1865) p. 370; CARRASCo (1874) pp. 124-125, resiente que este poder se le haya conferido al Presidente y no al Congreso. Es el caso del artículo 72 N 17 de la Constitución de 1925, que compendió varias normas de la Constitución anterior, concentrándolas expresamente en el Presidente de la República, Guerra (1929) p. 392; y los poderes del Presidente en caso de invasión extranjera son mayores que en la Constitución de 1833, Guerra (1929) p. 393. Un detenido análisis de este artículo de la Constitución de 1925 en Oliver (1945) pp. 61-80.

39 Respecto de la Constitución de 1833, LASTARRIa (1865) pp. 283-284, lamenta el modo tan amplio en que el Congreso ha interpretado el artículo $36 \mathrm{~N}^{\circ} 6$ y denosta la ley del 31 de enero de 1837, porque de hecho convirtió al Presidente en un "monarca absoluto". Huneeus (1890) Tomo I, p. 178, denuncia que la disposición del artículo $36 \mathrm{~N}^{\circ} 6$ se aplicó "de manera singularmente monstruosa". LASTARRIA (1865) pp. 479-480, critica también la amplitud con que el Presidente de la República ha interpretado el artículo 161, concentrando mucho mayor poder que el previsto por la norma; y CARrasco (1874) p. 196, habla del Presidente dictador que descansa en esta disposición. El artículo $82 \mathrm{~N}^{\circ} 20$ disponía la intervención del Congreso en los casos de conmoción interior, pero el Presidente burló fácilmente esta disposición decidiendo los Estados de Sitio por sí y ante sí, Lastarria (1865) pp. 371-373. Respecto de la Constitución de 1925, el artículo $44 \mathrm{~N}^{\circ} 3$ sirvió poco para limitar las atribuciones del Presidente. En la práctica, el Congreso se relajó y delegó en el Presidente amplios poderes. Tres buenos ejemplos son la LeY No 7.200 de 1942, la LEY Nº 12.927 de 1958, de Seguridad Interior del Estado, y la LEY N 13.959 de 1960, dictada tras el terremoto de ese año. ANDrADE (1963) pp. 304-308; SCHWEITZER (1972) pp. 134-137 y pp. 140-143.
} 
cambio, el texto de la Constitución puede plantear dudas razonables acerca de la primacía del Ejecutivo respecto del Poder Judicial. Pero la escasísima jurisprudencia habida desde entonces parece confirmar la supremacía del Presidente, contra lo que el texto en principio sugiere.

Antes de 2005 no se había insinuado en la institucionalidad la posibilidad de que un tribunal de justicia pudiera revisar los motivos que a juicio de la autoridad política justificaran la declaración de un estado de excepción constitucional. Las restricciones venían asociadas fundamentalmente a la participación del Congreso en la decisión política ${ }^{40} \mathrm{y}$ al control de la discrecionalidad de las medidas adoptadas durante las circunstancias extraordinarias, especialmente la aplicación de penas ${ }^{41}$. La reforma constitucional de 1874 y el artículo 44 $\mathrm{N}^{\circ} 13$ de la Constitución de 1925 podrían plantear la cuestión de si la primacía era del Congreso o del Presidente de la República, pero al afirmar así el carácter esencialmente político de la materia, el control judicial de tal poder naturalmente se entendía excluido ${ }^{42}$.

En la práctica, la articulación entre el Congreso y el Presidente deja muy poco espacio para negar que la primacía corresponde a este último. La Constitución de 1833 disponía que el Congreso podía delegar en el Presidente facultades extraordinarias para adoptar las medidas que hicieren falta para el mantenimiento del orden público (artículo $36 \mathrm{~N}^{\circ}$ 6). Las condiciones de tal delegación reforzaban la intención de reservar una decisión tan grave a la colegialidad del cuerpo legislativo ${ }^{43}$. Sin embargo, en los hechos, el Congreso renunció al ejercicio de esta facultad habilitando al Presidente para hacerlo según su discreción ${ }^{44}$. La reforma de 1874 intentó corregir este abuso y la Constitución de 1925 insistió en la misma dirección. Sin embargo, el Presidente ejerció de hecho este poder sin contrapeso político porque el Congreso fue su cómplice ${ }^{45}$.

En este contexto, la Constitución aprobada en 1980 sinceró lo que durante los decenios precedentes era una práctica encubierta, trasladando el centro de la decisión política al Presidente de la República. Lo mismo cabe decir respecto del control judicial del ejercicio del poder presidencial. Al declarar improcedentes los recursos de amparo y protección

\footnotetext{
40 Esta fue la finalidad de la reforma a los artículos $36 \mathrm{~N}^{\circ} 6$ y 161 de la Constitución, en 1874. La misma tendencia explica la redacción del artículo $44 \mathrm{~N}^{\circ} 13$ de la Constitución de 1925.

41 En el caso del Estado de Asamblea, es elocuente el oficio enviado por la Corte Suprema al Ministro de Guerra, en 1872, en el que condena el enorme margen de discrecionalidad con que se ha interpretado la Ordenanza Militar de 1839, en Huneeus (1890) Tomo II, pp. 479-482.

42 Un ejemplo elocuente es el debate habido en la Comisión Mixta que estudió un proyecto de ley sobre Estado de Sitio: versó exclusivamente sobre la distribución de poder entre el Congreso y el Presidente. ConGRESO Nacional, Informe de la Comisión Mixta especial de Senadores y Diputados recaído en la declaración del Estado de Sitio en diversos puntos del territorio nacional, pp. 718-733.

43 Hay que tener en cuenta que las facultades extraordinarias suspendían el imperio de la Constitución en la zona afectada.

44 RoldÁn (1915) p. 323, pone por ejemplo la LEY de 31 de enero de 1837, dictada con ocasión de la guerra con Perú: "[d]e acuerdo con esta ley, desapareció el Congreso y el Presidente quedó erigido en dictador [por dos años]".

45 Ver nota 39. GonzÁlez (2015) p. 104, reporta que la tendencia doctrinal en Chile hacia la decáda de los 60 "resaltaba la importancia del ejecutivo en la organización estatal" y, en consecuencia, "alimentaba la expansión de los estados de excepción”.
} 
contra los actos de la autoridad durante los estados de excepción constitucional ${ }^{46}$, el constituyente no hizo más que recoger lo que era la experiencia histórica ${ }^{47}$. La inmunidad jurisdiccional del Ejecutivo antes de la reforma de 1989 es casi obstinadamente confirmada por la disposición $24^{\mathrm{a}}$ transitoria, que los tribunales de justicia interpretaron en forma literal ${ }^{48}$.

Lo que la historia de los estados de excepción en Chile parece enseñarnos en el contexto de este trabajo son tres cosas. La primera es quizá obvia: el ámbito natural de las decisiones para enfrentar situaciones de excepción es el político. La segunda es que los tribunales de justicia no han tenido prácticamente margen alguno para controlar las actuaciones del poder político en tales situaciones. La tercera es que ha sido en el Presidente de la República en quien se ha incardinado el ejercicio de las potestades extraordinarias típicas de los estados de excepción. En otras palabras, la historia nos ofrece un conjunto de hechos que bien pueden interpretarse en favor de la primacía del Presidente como garante de la Constitución. Por supuesto que lo anterior no nos autoriza a concluir que así es como debe ser, pero sí nos permite pensar que tal vez haya buenos motivos para que así sea.

\section{LA DOCTRINA DEL ACTO POLÍTICO}

La discusión acerca del control judicial de la declaración de estados de excepción constitucional se enmarca en el problema más amplio de la inmunidad jurisdiccional del poder político, específicamente del Poder Ejecutivo. La doctrina conocida como de los actos de gobierno se ha desarrollado precisamente para justificar un espacio de autonomía política respecto del Poder Judicial en el esquema propio del Estado de Derecho ${ }^{49}$. Puesto que la declaración de un estado de excepción constitucional cabría entenderlo como un acto de gobierno, la incompetencia del Poder Judicial podría apoyarse en la doctrina señalada. Así piensan algunos autores nacionales.

Pfeffer, en su prevención en el caso Campos Herrera con Fisco de Chile, advirtió que la facultad presidencial para declarar afectada una zona de acuerdo con la Ley $\mathrm{N}^{\circ}$

\footnotetext{
46 El artículo $41 \mathrm{~N}^{\circ} 3$, hasta la reforma de 1989, declaró improcedente el recurso de protección y el recurso de amparo, aunque la restricción no fue absoluta. La disposición $24^{\mathrm{a}}$ transitoria declaró improcedente cualquier recurso que no fuera ante la misma autoridad que dictó el acto, lo que en tribunales se interpretó como una restricción prácticamente absoluta del recurso de amparo (ver nota 65).

47 El artículo 161 de la Constitución de 1833 facultaba al Ejecutivo con poderes extraordinarios durante el Estado de Sitio. Antes de la reforma de 1874, el Ejecutivo se valió de estas atribuciones para restringir la libertad ambulatoria sin contrapeso real por parte del Poder Judicial. Para Manuel Antonio Tocornal, en opinión sostenida en 1846, la correcta interpretación del artículo 161 era que el Estado de Sitio suspendía la libertad individual, equivalente a lo que en Inglaterra era la suspensión del habeas corpus, Huneeus (1890) Tomo II, p. 387. En el mismo sentido, LASTARRIA (1865) p. 479, y CARRASCO (1874) p. 195, quien equipara el artículo 161 a la suspension clause de la Constitución de los EE.UU. Después de la reforma de octubre de 1874, la modificación del artículo 161 reflejó la interpretación de Tocornal, que era la dominante entonces, Huneeus (1890) Tomo II, pp. 389-390. Respecto de la Constitución de 1925, el libro de Caffarena de Jiles (1957) prueba el nulo efecto que tenían los recursos de amparo dirigidos contra medidas adoptadas durante los estados de excepción constitucional.

48 Ver nota 65 y ss.

49 En Chile, en el último tiempo, el defensor más decidido de esta doctrina ha sido Francisco Zúñiga, especialmente en ZúNiga (1996) y ZúNiga (2008). También puede verse CEA (1991) y Atria (1993).
} 
16.282 es "privativa y excluyente del Ejecutivo" 50 . La razón para defender esta cualidad del actuar gubernamental, que en estos casos "importa el ejercicio de una atribución exclusiva y privativa de la autoridad política que escapa al control jurisdiccional" ${ }^{1}$, es el respeto al principio de separación de los poderes. Así, dice: "[a]dmitir que una decisión tal, en esencia un acto político o de gobierno, no justiciable, pueda ser evaluado en su mérito por la judicatura trastoca el principio de separación de funciones desde que abre cauce a un control en sede jurisdiccional que la Constitución Política entrega explícitamente a órganos políticos"52. La misma idea está presente en un trabajo suyo de 2002. Allí, sin renunciar a la premisa de que la potestad del Presidente debe estar siempre sujeta a control, se inclina porque este sea un control político. Aceptar que el poder jurisdiccional se extienda a revisar el mérito, conveniencia u oportunidad de declarar un régimen de excepción comporta una subrogación de roles que resulta inadmisible ${ }^{53}$.

Jorge Precht también ha defendido la inmunidad jurisdiccional del Presidente de la República para declarar un estado de excepción constitucional basado en la doctrina de los actos de gobierno. Para este autor, el acto declarativo es un acto institucional, es decir, un tipo de acto de gobierno o político que se caracteriza por estar contemplado en la Constitución y regular "las relaciones entre los poderes del Estado, emanando directamente de una potestad constitucionalmente establecida" 54 . Respecto de estos actos, dice, los tribunales ordinarios carecen de competencia para controlarlos ${ }^{55}$. Precht defiende esta postura contra la tesis de que cabría un control jurisdiccional de dichos actos a través del recurso de protección ${ }^{56}$, porque los actos institucionales no inciden "directa e inmediatamente en la esfera jurídica del administrado" y, por tanto, están fuera de los "negocios" que compete a los tribunales conocer, en el lenguaje del artículo 76 de la Constitución ${ }^{57}$.

50 Campos Herrera con Fisco de Chile (2013).

51 Campos Herrera con Fisco de Chile (2013).

52 Campos Herrera con Fisco de Chile (2013). Pfeffer se siente en la obligación de equiparar las atribuciones presidenciales de la LeY N 16.282 de 1965 (zona afectada) con las de la Constitución (estados de excepción), frente a la posición de la mayoría, que eludió la cuestión de la justiciabilidad del decreto que declara zona afectada.

53 Resulta un tanto ambigua la posición en PfefFer (2002) p. 16, porque antes ha dicho que en determinados casos "parece lógico establecer (...) un control jurídico" sobre los requisitos formales para declarar un estado de excepción constitucional.

54 Precht (1996) p. 245.

55 PRECHT (1996) p. 246.

56 Alude a Eduardo Soto Kloss como referencia de esta tesis, pero no precisa la fuente. Podría estar refiriéndose a Soto (1982) p. 429-63, en particular pp. 436-439. Aunque aquí Soto Kloss se enfoca particularmente en el control de las medidas adoptadas por la autoridad durante un estado de excepción, podría extenderse el alcance de sus premisas al control de la declaración del estado de excepción.

57 Precht (1996) p. 248. La posición de Precht tiene una brecha teórica. Si bien afirma "la falta absoluta de jurisdicción de los Tribunales Ordinarios para conocer de los actos institucionales": PrECHT (1996) p. 247, vacila al preguntarse "¿Qué pasa si en el ejercicio de estos actos institucionales se cometiere una abierta arbitrariedad?": Precht (1996) p. 249. Porque entonces responde: “en caso de abierta arbitrariedad o violación clara de principios generales del derecho (...) el Poder Público no habría hecho un ejercicio legítimo de su potestad constitucional y en consecuencia cabría el recurso de protección o amparo": PRECHT (1996) p. 250. Lo segundo es incompatible con declarar "la falta absoluta de jurisdicción". 
Quien más resueltamente ha defendido la inmunidad de la potestad presidencial frente al control jurisdiccional ha sido Zúñiga. Comentando el texto del artículo 41D (actual 45 inciso $^{\circ}$ ) de la Constitución, después de la reforma constitucional de 2005, dice que "conserva el distingo entre acto político o de gobierno y actos de la Administración" y que "[l]a declaración de estado de excepción es un típico acto político no justiciable" 58 . Luego, en su comentario a la sentencia Campos Herrera con Fisco de Chile, defiende la inmunidad jurisdiccional de esta potestad del Presidente en el contexto del activismo judicial. Celebra que la Corte Suprema haya rescatado el acto de gobierno, "que para muchos es una pieza de museo, un trasto viejo de la batalla contra las inmunidades del poder", porque "no es una pieza oxidada" 59 . Frente a quienes postulan el control judicial sin límites como la piedra angular del Estado de Derecho ("letrados imbuidos de panjudicialismo", los califica), la doctrina del acto de gobierno ofrece "la plasticidad práctica exigida por los gobernantes situados en la sala de máquinas del Estado"60. El derecho de excepción es uno de los pocos respiraderos que salvan al poder político de ser sofocado por el Poder Judicial y una defensa contra el "gobierno de los jueces incompatible con el orden republicano democrático y el imperio de la ley" ${ }^{6}$.

\section{E. LA JURISPRUDENCIA DEL ACTO POLítico}

Sentencias como las del juicio Campos Herrera con Fisco de Chile, en donde se impugna en sede judicial la declaración de un estado de excepción constitucional, no conocemos más que otras dos, motivadas por las mismas circunstancias que esta sentencia ${ }^{62}$. Sin embargo, nuestros tribunales han tenido múltiples ocasiones para pronunciarse acerca de medidas adoptadas durante un estado de excepción constitucional, especialmente relacionadas con la libertad personal. En esas sentencias es posible identificar una posición jurisprudencial dominante, expresada de manera más o menos explícita.

En su libro "El Recurso de Amparo frente a los Regímenes de Emergencia", Caffarena de Jiles hace un ilustrativo recuento de la jurisprudencia habida hasta 1957. Después de afirmar la competencia del Poder Judicial para defender la libertad personal en los distintos regímenes de excepción entonces vigentes, constata que todos los fallos - "sin que pueda

58 ZúNiga (2005) p. 184; ZúNíga (2014) p. 518. El mismo autor lamenta que la reforma constitucional de 2005 haya reducido el campo del acto político en el derecho de excepción, esto es, la declaración de un estado de excepción, a su mínima expresión: ZúNIGA (2008).

59 ZÚNiga (2014) p. 521.

60 ZúNíga (2014) p. 521.

${ }_{61}$ ZúNíiga (2014) p. 522. Habría que mencionar también a RodRíGueZ (1961), que comprende la declaración del Estado de Sitio en el conjunto de los actos de gobierno y, por lo tanto, no impugnable ante los tribunales de justicia.

62 Aravena Pacheco y otros con Fisco de Chile (2014) y Guzmán y otros con Fisco de Chile (2014). Además de la jurisprudencia judicial, hay jurisprudencia administrativa. La Contraloría General de la República, en su Dictamen N 33441 de 1982, definió que "la verificación de la existencia y la calificación de los hechos que configuran una determinada situación de excepción competen privativamente a las autoridades que la Constitución establece, y deben formalizarse a través de la declaración del respectivo estado de excepción constitucional". También es útil el Dictamen N 40756 de 1976, por el que la Contraloría definió que el "jefe militar de la zona en estado de emergencia tiene facultades para (...) certificar los hechos que sirven de fundamento a la medida [adoptada], sin que Contraloría pueda intervenir en tales facultades privativas". 
señalarse un solo caso de excepción"- han rechazado los recursos de amparo ${ }^{63}$. Lo interesante es el motivo: "[h]a estimado nuestra autoridad judicial que le está vedado calificar los antecedentes en que se fundan" las órdenes de detención y traslado decretadas por el Presidente de la República. Y este motivo refleja la concepción que los jueces tienen acerca de la naturaleza del acto. Aunque se la exprese de diversas maneras, dicha concepción revela en el fondo la doctrina del acto de gobierno o acto político, que se funda en el respeto a la separación de los poderes ${ }^{64}$.

Esta jurisprudencia se replicó en la aplicación de la disposición $24^{a}$ transitoria de la Constitución, aunque con distinta intensidad entre 1981 y 2005, cuando se derogó. La interpretación de la frase "no procederá recurso alguno" sirvió para justificar el rechazo casi sistemático de los recursos interpuestos, declarándolos improcedentes ${ }^{65}$. La distinción entre la faz política y la faz jurídica del acto de autoridad no sirvió para alentar el control judicial de la legalidad de la actuación ${ }^{66}$. Una premisa recurrente en estos casos fue que los jueces no pueden calificar los antecedentes o fundamentos de hecho de la decisión, extendiendo el alcance de la prohibición del artículo $41 \mathrm{~N}^{\circ} 3$ inciso final.

Implícito en la posición de los tribunales puede verse el reconocimiento de la naturaleza política de la decisión y la consiguiente incompetencia judicial para juzgarla. Aunque la jurisprudencia se ha elaborado en función de las medidas dictadas durante los estados de excepción, es un antecedente muy ilustrativo cuando se la pone en el contexto del poder para declarar los estados de excepción. Porque si los tribunales son incompetentes para juzgar las actuaciones que se enmarcan en situaciones de excepción, cuánto más lo serán para controlar la decisión que las ampara a todas ellas ${ }^{67}$.

\section{F. El caso de Francia}

El Derecho francés ofrece un buen ejemplo de la inmunidad jurisdiccional del acto declarativo de un estado de excepción constitucional ${ }^{68}$. En ese país, la decisión presidencial de invocar los poderes excepcionales del artículo 16 de la Constitución está exenta de control judicial porque es un acto de gobierno; y es un acto de gobierno porque su naturaleza es eminentemente política ${ }^{69}$.

63 Caffarena de Jiles (1957) p. 221.

${ }^{64}$ Lo resume Patricio Aylwin en el prólogo al libro: "[la posición de los tribunales] se apoya fundamentalmente en lo dispuesto por el art. 4 del Código Orgánico de Tribunales, que prohíbe al Poder Judicial mezclarse en las atribuciones de los otros poderes públicos": CAFFARENA DE JiLes (1957) p. 14.

65 Ríos (1983) p. 792. Ríos (2005) p. 338-339, cuantifica en "miles" los recursos de amparo rechazados. TAVOLARI (1995) p. 72, cifra entre 10.000 y 12.000 los recursos de amparo deducidos, de los que no se acogió ni el $1 \%$.

${ }^{66}$ Ríos (1983) pp. 789-791. García (2005) pp. 451-452, afirma que la facultad presidencial se ejerció "sin control judicial alguno".

${ }^{67}$ Aquí vale la versión negativa del apotegma qui potest plus, potest minus: quien no puede lo menos, no puede lo más.

68 Aparte de otras razones, el Derecho francés es una referencia casi obligada por la influencia que ha tenido en la jurisprudencia local sobre recursos de amparo durante estados de excepción constitucional. CAFFARENA DE JiLEs (1957), pp. 223-224.

69 En la génesis de esta disposición está la experiencia de 1940, cuando Francia, invadida por el ejército alemán, fue incapaz de reaccionar adecuadamente, Documents D’Études (1970) pp. 2 y 5. Fue una de las 
El artículo 16 de la Constitución establece las condiciones bajo las cuales el Presidente de la República puede adoptar las medidas para restablecer la normalidad alterada por circunstancias extraordinarias ${ }^{70}$. Hay condiciones de forma y de fondo. Si bien de unas y otras el Presidente es el único intérprete, son las de fondo las que más interesan, por el mayor margen de apreciación que su texto admite; la ponderación que él haga de las circunstancias que justifican los poderes excepcionales es soberana ${ }^{71}$, y solo cabe respecto de ella un eventual control político ${ }^{72}$.

La sentencia del Consejo de Estado Rubin de Servens, del 2 de marzo de 1962, hubo de pronunciarse acerca de la demanda interpuesta por varios soldados franceses, presos por su participación en el golpe de abril de 1961. Específicamente, debió resolver sobre la nulidad por exceso de poder de la decisión del Presidente de la República, del 3 de mayo de 1961, de instituir un tribunal militar para juzgarlos. El Consejo de Estado rechazó la demanda por ser incompetente para conocerla, pues la creación de dicho tribunal se enmarca en los poderes del artículo 16 de la Constitución, que "habilita al Presidente para adoptar todas las medidas exigidas por las circunstancias que han motivado su aplicación"73. Y la decisión de aplicar el artículo 16 de la Constitución "presenta el carácter de un acto de gobierno y, por lo tanto, no le corresponde al Consejo de Estado juzgar su legalidad ni controlar su duración" 74 .

La categoría de los actos de gobierno es una creación jurisprudencial de larga tradición en el Derecho francés ${ }^{75}$. Aunque el ámbito de su aplicación se haya ido restringiendo con el tiempo, su fundamento permanece intacto: hay actos que por su naturaleza escapan a la competencia de los órganos jurisdiccionales ${ }^{76}$. Esta doctrina de los actos de gobierno pivota sobre la concepción francesa de la separación de los poderes, especialmente recelosa de las incursiones judiciales en política. Es, por lo demás, perfectamente compatible con el

innovaciones más controvertidas del proyecto constitucional del General De Gaulle y con frecuencia se ha propuesto su revisión, la última con ocasión del atentado terrorista del 13 de noviembre de 2015: véase por ejemplo Le MONDE (2015).

70 Los poderes excepcionales del artículo 16 de la Constitución son una de las respuestas del Derecho francés a las situaciones de crisis institucional. Las otras son el Estado de Sitio (LEY de 9 de agosto de 1849 y artículo 36 de la Constitución) y el Estado de Urgencia (Ley N ${ }^{\circ}$ 55-385 de 1955). También podría incluirse la doctrina de las circunstancias excepcionales del Conseil d'État: HeYriés (1918).

71 Pactet et Mélin-Soucramanien (2006) p. 428.

72 La obligación que el Presidente tiene de consultar al Consejo Constitucional no debe entenderse como un mecanismo de control jurisdiccional, porque la respuesta de dicho órgano no es vinculante. La función del Consejo Constitucional es constatar una situación excepcional, FAVOrEAU et al. (2006) pp. 295-296.

73 Rubin de Servens (1962). Es de notar que el artículo 16 de la Constitución no precisa el rango de medidas que pueden adoptarse ni hace referencia a los derechos fundamentales como límite de tales medidas.

74 Rubin de Servens (1962).

75 Su reconocimiento por parte del Consejo de Estado se remonta a comienzos del siglo XIX: LAFFITTE (1822).

76 Chapus (2001) pp. 948-950: la diferencia entre actos de gobierno (no justiciables) y actos administrativos (justiciables) parece innegable, pero la frontera entre unos y otros es difícil de trazar. Hay varios criterios útiles, no obstante. 
principio de supremacía constitucional, del que el artículo 5 de la Constitución se hace eco cuando dispone que al Presidente de la República toca velar por su respeto ${ }^{77}$.

En suma, el recurso a los poderes excepcionales del artículo 16 de la Constitución "está entregado a la discreción del Presidente de la República y no reconoce más límites que los que él mismo se fije"78.

\section{CONCLUSIÓN}

Existen buenos argumentos tanto a favor como en contra de la tesis de que la decisión sobre los estados de excepción constitucional implica una interpretación política de la Constitución, en la que el Presidente de la República tiene la última palabra. Esta suerte de empate refleja el equilibrio en tensión que existe entre dos principios básicos del constitucionalismo presentes en este supuesto, la separación de los poderes y su control mutuo.

Los argumentos de la sección III proyectan el principio del control mutuo, en este caso el que ejerce el Poder Judicial sobre el Ejecutivo. En cambio, los argumentos de la sección IV adquieren todo su sentido en el contexto del principio de separación de los poderes, porque afirman la independencia del Presidente de la República respecto de los tribunales de justicia en el ejercicio de una de sus atribuciones específicas.

Los dos principios se complementan entre sí, relativizándose su alcance, porque, así como resulta inviable una separación total de los poderes, así lo es también un control total. Su articulación, en consecuencia, se materializa en las variadas combinaciones que ofrece la distinta naturaleza de los controles propios de cada poder. Esto significa que si bien todos los actos están sujetos a algún tipo de control, ningún poder tiene el control sobre todos los actos. En la línea de este trabajo, la cuestión no es, por tanto, si la declaración de un estado de excepción constitucional es un acto exento de control, sino si acaso está eximido del control judicial.

La experiencia nos enseña que la declación de un estado de excepción constitucional es un acto eximido del control judicial. Hasta aquí, el Presidente de la República ha ocupado la posición casi indiscutida de garante último de la Constitución, en relación con las condiciones que configuran una situación de excepción. Esta circunstancia es avalada por una concepción del principio de separación de los poderes, que se expresa en los distintos argumentos desarrollados en la sección IV. La frase del artículo 45 inciso $1^{\circ}$ que dice "sin perjuicio de lo dispuesto en el artículo 39" es lo único que impide afirmar limpiamente que en Chile la potestad presidencial para declarar un estado de excepción constitucional está libre del control judicial. Existen muy buenas razones para defender la inmunidad jurisdiccional del Presidente de la República en el ejercicio de esta atribución específica, pero es

\footnotetext{
En este sentido, el Consejo de Estado estimó que la derogación del artículo 16, propuesta por François Mitterrand en 1993, privaría al Presidente de la República, en caso de circunstancias excepcionales cuya eventualidad no puede excluirse absolutamente, "de los medios apropiados de cumplir con las obligaciones que le incumben, en virtud del artículo 5, de asegurar el funcionamiento regular de los poderes públicos así como la continuidad del Estado", citado en SAinT-Bonnet (1998) p. 1699.

78 Pactet et Mélin-Soucramanien (2006) p. 428. Lo mismo vale para su duración y para los actos dictados en aplicación de estos poderes, a menos que caigan en el ámbito reglamentario. Sobre esto último, GUETTIER (1998) pp. 1729-1730.
} 
innegable que el texto de la Constitución después de la reforma de 2005 ha abierto la posibilidad de que el Poder Judicial se erija como el intérprete final del derecho de excepción. Mientras esto no ocurra, sin embargo, el Ejecutivo seguirá siendo el guardián último de la supremacía constitucional. Y sentencias como Campos Herrera con Fisco de Chile sugieren que a la Corte Suprema le parece bien que así sea.

\section{BIBLIOGRAFÍA CITADA}

Andrade, Carlos (1963): Elementos de Derecho Constitucional chileno (Santiago, E d ito rial Jurídica de Chile).

AtRia, Fernando (1993): "Comentario a la sentencia recaída sobre el caso Cereceda", Revista de Derecho y Humanidades, año II No 3 y 4: pp. 229-238.

Bravo, Clodomiro y Sharim, Nissim (1958): Restricciones a las libertades públicas (Santiago, Editorial Jurídica).

CAFFARENA DE JiLES, Elena (1957): El recurso de amparo frente a los regímenes de emergencia (Santiago, s. e.).

Carrasco, Manuel (1874): Comentarios sobre la Constitución Política de 1833 (Santiago, Imprenta de la Librería del Mercurio, $2^{a}$ edición).

Castillo, Jaime (1986): Democracia y derechos humanos (Santiago, Pehuén Editores).

CEA, José Luis (1991): "Fiscalización política o control judicial del acto de gobierno", Gaceta Jurídica, $\mathrm{N}^{\circ}$ 137: pp. 9-34.

Chapus, René (2001): Droit Administratif Général, Tome 1 (Paris, Montchrestien, $15^{\text {a édi- }}$ tion).

Cifuentes, Eduardo (2002): "Los Estados de Excepción Constitucional en Colombia”, Ius et Praxis, Vol. 8 № 1: pp. 117-146.

ECHEverri, Sebastián (2014): "Los estados de excepción en Colombia: un estudio de caso”, Revista CES Derecho, núm. 5, pp. 6-17.

Favoreau, Louis et al. (2006): Droit constitutionnel (París, Dalloz).

Fontecilla, Mariano (1953): "Facultad o jurisdicción de los tribunales ordinarios para conocer de ciertas materias relacionadas con decretos del Presidente de la República”, Revista de Derecho y Jurisprudencia, Tomo L, № 7 y 8: pp. 75-84.

Gallón, Gustavo (1979): Quince años de estado de sitio en Colombia: 1958-1978 (Bogotá, Ediciones Guadalupe).

García, Gonzalo (2005): "Los estados de excepción constitucional: un nuevo derecho de excepción”, en Reforma Constitucional (Santiago, LexisNexis) pp. 451-476.

GonZÁlez, Jorge (2015): Estados de excepción y democracia liberal en América del Sur: Argentina, Chile y Colombia (1930-1990) (Bogotá, Editorial Pontificia Universidad Javeriana).

Guerra, José (1929): La Constitución de 1925 (Santiago, Establecimiento Gráficos Balcells \& Co.).

Guettier, Christophe (1998): "Le contrôle juridictionnel des actes du président de la République", Revue du Droit Public, No 5-6: pp. 1719-1747.

HuneEus, Jorge (1890): La Constitución ante el Congreso, Tomo I y II (Santiago, Imprenta Cervantes, $2^{\mathrm{a}}$ edición). 
Lastarria, José Victorino (1865): Elementos de Derecho Público Constitucional Teórico, Positivo y Politico (Gante, Kessinger Legacy Reprints, $3^{\mathrm{a}}$ ed. facsimilar).

Oliver, Carlos (1945): De las garantías individuales y del Estado de Sitio (Valparaíso, Escuela Tipográfica Salesiana).

Pactet, Pierre et Mélin-Soucramanien, Ferdinand (2006): Droit constitutionnell (Paris, Dalloz, 25ádition).

PFEFFER, Emilio (2002): "Estados de excepción constitucional y reforma constitucional", Ius et Praxis, Vol. 8, № 1: pp. 223-250.

Precht, Jorge (1996): "La declaración de los estados de excepción como un acto institucional", en Los Estados de Excepción en Chile (Santiago, Corporación Nacional de Reparación y Reconciliación): pp. 241-250.

Ríos, Lautaro (1983): "La Disposición 24 Transitoria ante el Estado de Derecho", Revista Chilena de Derecho, Vol. 10: pp. 781-806.

Ríos, Lautaro (2005): "Los Estados de Excepción Constitucionales en una Perspectiva Humanista”, en La Constitución Reformada de 2005 (Santiago, Centro de Estudios Constitucionales): pp. 319-344.

Ríos, Lautaro (2009): "Defensa Judicial de los Derechos Humanos en los Estados de Excepción”, Estudios Constitucionales, Año 7, № 1: pp. 277-296.

Risopatrón, Carlos (1900): Ley de organización y atribuciones de los Tribunales de Chile y comentarios ordenados con el objeto de hacer más fácil su estudio (Imprenta y Litografía y encuadernación Barcelona).

Rodríguez, José A. (1961): Protección jurisdiccional de los administrados (Santiago, Editorial Jurídica de Chile).

Roldán, Alcibíades (1913): Elementos de Derecho Constitucional de Chile (Santiago, Imprenta, Litografía i Encuadernación Barcelona).

SAINT-Bonnet, Francois (1998): "Réflexions sur l'article 16 et l'état d'exception”, Revue de Droit Public, N 5-6: pp. 1699-1718.

SchWeItZer, Daniel (1972): Acusación constitucional (Santiago, Editorial Andrés Bello).

Silva, Alejandro (1986): "Ámbito de la función judicial en los estados de excepción", Revista Chilena de Derecho, Vol. 13: pp. 81-99.

Sото KLoss, Eduardo (1982): El recurso de protección. Origenes, doctrina y jurisprudencia (Santiago, Editorial Jurídica de Chile).

TAVOlaRI, Raúl (1995): Habeas corpus: recurso de amparo (Santiago, Editorial Jurídica de Chile).

VAnegas, Pablo (2011): "La constitución colombiana y los estados de excepción: veinte años después”, Revista Derecho del Estado, № 27: pp. 261-290.

ZúNIGA, Francisco (1996): "Recurso de protección y sistema político", Revista de Derecho Universidad de Concepción, No 199 Año LXIV: pp. 105-120.

ZúNIGG, Francisco (2005): "Libertad y autoridad en el derecho constitucional: El derecho de excepción”, Revista de Derecho Público, Vol. 67: pp. 170-190.

ZúNigA, Francisco (2008) "Control judicial de los actos políticos: recurso de protección ante las 'cuestiones políticas'", Ius et Praxis, Vol. 14, No 2: pp. 271-307.

ZúNiga, Francisco (2014): "El Derecho de Excepción y la Responsabilidad del Estado: Falta de Servicio y Acto de Gobierno. Comentario de la Sentencia de Casación Rol 
4029-2013 de la Corte Suprema, de 24 de Diciembre de 2013”, Estudios Constitucionales, Año 12: pp. 503-526.

\section{JURISPRUDENCIA CITADA}

Campos Herrera con Fisco de Chile (2013): Corte Suprema, 24 de diciembre de 2013 (indemnización de perjuicios extracontractuales), rol 4029-2013, en www.pjud.cl. Fecha de consulta 21 de abril de 2017.

Aravena Pacheco y otros con Fisco de Chile (2014): Corte Suprema, 12 de agosto de 2014 (indemnización de perjuicios extracontractuales), rol 6143-2014, en www.pjud.cl Fecha de consulta 21 de abril de 2017.

GuZMÁn y otros con Fisco de ChILe (2014): Corte Suprema, 12 de agosto de 2014 (indemnización de perjuicios extracontractuales), rol 2839-2014, en www.pjud.cl. Fecha de consulta 21 de abril de 2017.

Corte Constitucional de Colombia, 7 de mayo de 1992 (revisión constitucional de decreto), C-004-92, en www.corteconstitucional.gov.co. Fecha de consulta 6 de octubre de 2017.

Corte Constitucional de Colombia, 1 de julio de 1994 (revisión constitucional de decreto), C-300-94, en www.corteconstitucional.gov.co. Fecha de consulta 6 de octubre de 2017.

Corte Constitucional de Colombia, 18 de octubre de 1995 (demanda de inconstitucionalidad de decreto ley), C-222-95, en www.corteconstitucional.gov.co. Fecha de consulta 6 de octubre de 2017.

Corte Constitucional de Colombia, 29 de abril de 1997 (control de constitucionalidad de proyecto de ley), C-466-97, en www.corteconstitucional.gov.co. Fecha de consulta 6 de octubre de 2017.

Corte Constitucional de Colombia, 2 de octubre de 2002 (revisión constitucional de decreto), C-802-02, en www.corteconstitucional.gov.co. Fecha de consulta 6 de octubre de 2017.

LAFFiTTE (1822): Conseil de État, 1 de mayo de 1822 (nulidad de decreto), $\mathrm{N}^{\circ}$ 5363, en www.revuegeneraledudroit.eu/blog/decisions/conseil-detat-ord-1-mai-1822-laffitterequete-numero-5363-rec-1821-1825-p-202/. Fecha de consulta 6 de octubre de 2017.

HeYriés (1918): Conseil de État, 28 de junio de 1918 (nulidad de decreto), Nº 63412, en www.conseil-etat.fr. Fecha de consulta 6 de octubre de 2017.

Rubin de Servens (1962): Conseil de État Ass., 2 de marzo de 1962 (nulidad de decreto), $\mathrm{N}^{\circ}$ 55049, en www.conseil-etat.fr. Fecha de consulta 6 de octubre de 2017.

\section{NORMAS CITADAS}

Constitución Política de la República Chilena (1833)

Constitución Política de la República de Chile (1925)

Acta Constitucional No 4 (13/9/1976)

Constitución Política de la República de Chile (1980)

Constitución Política de Colombia (1991), Consejo Superior de la Judicatura, Sala Administrativa y Centro de Documentación Judicial (Cendoj), en www.corteconstitucional.gov.co. Fecha de consulta 6 de octubre de 2017. 
Constitución Francesa (1958), en www.legifrance.gouv.fr. Fecha de consulta 6 de octubre de 2017.

Ley de Organización y Atribuciones de los Tribunales (1875)

Código Orgánico de Tribunales (1943)

LEY N 7.200 (21/7/1942), Otorga facultades extraordinarias al ejecutivo para dictar disposiciones de carácter administrativo, económico y financiero.

LEY N ${ }^{\circ} 12.927$ (6/8/1958), de Seguridad Interior del Estado.

LEY $\mathrm{N}^{\circ} 13.959$ (5/7/1960), Aprueba medidas jurídicas en beneficio de las provincias que señala

LEY N 18.825 (17/8/1989), Modifica la Constitución Política de la República de Chile.

LEY No 20.050 (26/8/2005), Modifica la Constitución Política de la República de Chile.

Decreto Ley No 1684 (31 de enero de 1977), Sustituye el artículo 14 del Acta Constitucional $\mathrm{N}^{\circ} 4$.

Decreto Supremo No $150(2 / 3 / 2010)$.

DeCRETO Supremo No $153(2 / 3 / 2010)$.

Decreto Supremo No $792(5 / 3 / 2010)$.

Dictamen N 40756 de la Contraloría General de la República (14/6/1976).

Dictamen N 33441 de la Contraloría General de la República (29/10/1982).

\section{OTRAS FUENTES}

Actas Comisión de Estudios de la Nueva Constitución. En www.bcn.cl/lc/cpolitica/actas_oficiales-r. Fecha de consulta 6 de octubre de 2017.

Congreso de Chile: Informe de la Comisión Mixta Especial de Senadores y Diputados, recaído en la Declaración de Estado de Sitio en Diversos Puntos del Territorio Nacional. Diario de Sesiones del Senado, 1954, Sesión 15ª, pp. 718-733.

Documents D'Études: “L'Article 16 de la Constitution de 1958”. Documents d'Études $N^{\circ}$ 7, La Documentation Francaise, Mars, 1970, pp. 1-16.

Historia de LA Ley 20.050. En www.bcn.cl/historiadelaley. Fecha de consulta 6 de octubre de 2017.

Le Monde: "Etat d'urgence et article 16: pourquoi Hollande veut-il réviser la Constitution?", 16 de noviembre de 2015. En www.lemonde.fr/les-decodeurs/article/2015/11/16/etat-d-urgence-et-article-16-pourquoi-hollande-veut-il-reviser-la-constitution_4811353_43557 70.html. Fecha de consulta 6 de octubre de 2017. 